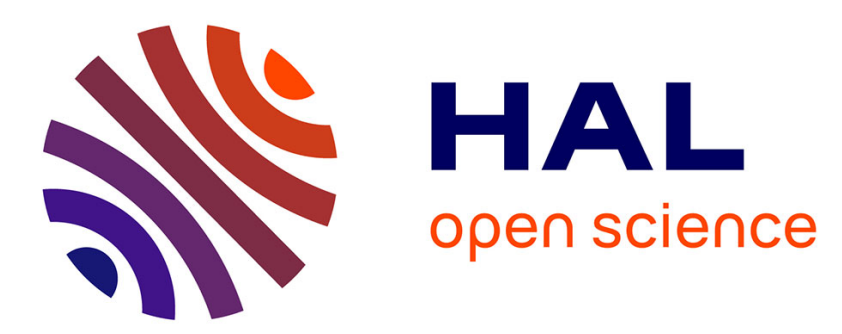

\title{
Modeling of Dynamic Current Distribution in REBCO Insulated Coils Using a Volume Integral Formulation for Protection Purpose
}

\author{
Blandine Rozier, Badel Arnaud, Brahim Ramdane, Gérard Meunier
}

\section{- To cite this version:}

Blandine Rozier, Badel Arnaud, Brahim Ramdane, Gérard Meunier. Modeling of Dynamic Current Distribution in REBCO Insulated Coils Using a Volume Integral Formulation for Protection Purpose. IEEE Transactions on Applied Superconductivity, 2019, 29 (5), 10.1109/TASC.2019.2903046 . hal02350897

\section{HAL Id: hal-02350897 \\ https://hal.science/hal-02350897}

Submitted on 30 Mar 2021

HAL is a multi-disciplinary open access archive for the deposit and dissemination of scientific research documents, whether they are published or not. The documents may come from teaching and research institutions in France or abroad, or from public or private research centers.
L'archive ouverte pluridisciplinaire HAL, est destinée au dépôt et à la diffusion de documents scientifiques de niveau recherche, publiés ou non, émanant des établissements d'enseignement et de recherche français ou étrangers, des laboratoires publics ou privés. 


\title{
Modeling of Dynamic Current Distribution in REBCO Insulated Coils Using a Volume Integral Formulation for Protection Purpose
}

\author{
B. Rozier ${ }^{(0)}$, A. Badel ${ }^{(1)}$, B. Ramdane, and G. Meunier ${ }^{(1)}$
}

\begin{abstract}
Dynamic current distribution in HTS coils submitted to current ramps induces a varying inductive voltage, which can be problematic for safe quench detection as its order of magnitude may hide the increasing dissipative voltage appearing at the beginning of a transition. In order to estimate the transient voltage component, which depends on the coil geometry as well as the current profile and the coil magnetization state, we developed a model using a Volume Integral formulation based on a generalization of the Partial Element Equivalent Circuit method. The objective is to split the coil's voltage end-to-end value into an inductive and a dissipative component so as to evaluate a safe voltage threshold value to implement in the detection system, enabling early transition detection to prevent the coil from major damages. The model is compared to experimental data and its application to coil's protection is detailed on a small-scale test coil.
\end{abstract}

Index Terms-HTS coils, quench propagation, protection, modeling.

\section{INTRODUCTION}

$\mathbf{H}$ IGH Temperature Superconductors (HTS) distinguish themselves from Low Temperature Superconductors as they exhibit high critical current densities, $\mathrm{J}_{\mathrm{c}}$, up to magnetic fields higher than $40 \mathrm{~T}$, making them particularly attractive for high field generation. Promising projects have the objective to develop and test HTS magnet technologies as for instance in the National High Magnetic Field Laboratory of Tallahassee which successfully designed a $32 \mathrm{~T}$ hybrid LTS-HTS magnet [1] or in Japan, at Tohoku University, where a cryogen-free superconducting magnet project is under progress [2]. However, the high thermal stability of coated conductor tapes combined with inhomogeneous critical current $\mathrm{I}_{\mathrm{c}}$ can create damaging hot spots when operating close to the critical conditions. When ramping up the magnet, the inductive voltage measured is several order of magnitude higher than the dissipative component that would appear at the very beginning of a transition. Besides, this transient

B. Rozier, B. Ramdane, and G. Meunier are with CNRS, Grenoble INP, G2Elab, Univ. Grenoble Alpes, 38000 Grenoble, France (e-mail: blandine. rozier@g2elab.grenoble-inp.fr; brahim.ramdane@g2elab.grenoble-inp.fr; gerard.meunier@g2elab.grenoble-inp.fr).

A. Badel was with CNRS, Grenoble INP, G2Elab, Univ. Grenoble Alpes, 38000 Grenoble, France. He is now with Tohoku University, Sendai 980-8577, Japan (e-mail: arnaud.badel@neel.cnrs.fr). voltage is varying with transport current increase because of the complex current distribution inside each turn which results in a varying inductance value [3]. As a result, if a local dissipative region appears, its voltage contribution may be completely hidden by the inductive component of the coil's voltage end-to-end measurement until it is too late to avoid damages. Thus, an estimation of the inductive voltage which depends on coil geometry and transport current (both value and ramp rate) could help to define safe threshold value based on the monitored signal order of magnitude, i.e., the magnet's terminal voltage drop. To deal with this problem, we developed a transient nonlinear electromagnetic model based on a Volume Integral Formulation which accounts for the critical current density dependency over the magnetic field, both magnitude and incident angle.

\section{VOLUME INTEGRAL FORMULATION}

Electromagnetic models of HTS devices using the Finite Element Method (FEM) have already been tested successfully by other teams, especially for AC losses computations [4]-[7], but meshing (high aspect ratio of coated conductors layers) as well as nonlinear convergence issues make these methods quite challenging to use [8]. We propose a more flexible approach based on a Volume Integral Formulation associated to the Partial Element Equivalent Circuit (PEEC) method [9] and adapted to 2D axisymmetric problems, whose main advantage is to require a mesh for active regions only, particularly convenient for RE$\mathrm{BCO}$ coil modeling as the active regions are only defined by the very thin superconducting layer (as long as the tape is not transiting, otherwise all conducting layers should be considered too, as well as a thermal coupling). Much less widespread than FEM within the superconductor modelling community, it has nevertheless been used for AC computations [10], [11]. In this paper, however, it is applied to the DC case of a REBCO magnet ramped up with the objective to estimate the impact of dynamic current distribution.

\section{A. The 2D Axisymmetric J-Formulation}

The J-formulation is derived from Maxwell's equations. The electric field is expressed through the use of a magnetic vector potential A and a scalar electric potential V such as

$$
\mathbf{E}=-\frac{\partial \mathbf{A}}{\partial \mathrm{t}}-\nabla \mathrm{V}
$$


The vector potential A can originate both from the current flowing through the superconducting material, written $\mathbf{A}_{\mathrm{sc}}$, and from an external magnetic field source, written $\mathbf{A}_{0}$.

$$
\mathbf{A}=\mathbf{A}_{0}+\mathbf{A}_{\mathbf{s c}}(\mathbf{J})
$$

The component induced by the current density $\mathbf{J}$ can be computed analytically in 3D using the Biot-Savart's law.

$$
\mathbf{A}_{\mathbf{s c}}(\mathbf{J})=\frac{\mu_{0}}{4 \pi} \int_{\Omega_{\mathrm{c}}} \frac{\mathbf{J}}{\mathrm{r}} \mathrm{d} \Omega_{\mathrm{c}}
$$

where $\mu_{0}$ is the vacuum permeability, $\mathrm{r}$ is the distance between the source and the computation points and $\Omega_{\mathrm{c}}$ is the conducting domain. However, modelling HTS coils in 3D is unnecessary as they exhibit an axial symmetry (provided that critical current density inhomogeneities observed along the conductor length are not taken into account) which enables to significantly reduce the size of the problem. Thus, in the cylindrical coordinate frame $(\mathrm{r}, \theta, \mathrm{z})$, all quantities are considered $\theta$-independent and the geometry is reduced to a cross-section of the coil containing its central axis. Moreover, an axisymmetric source field generation $\mathbf{A}_{0}$ is assumed, resulting in a $\mathbf{J}$ flow perpendicular to the crosssection and a vector potential oriented along the $\theta$-direction. Therefore, $\mathbf{A}_{\mathrm{sc}}$ and $\mathbf{J}$ quantities can be expressed as follow

$$
\begin{aligned}
\mathbf{J} & =\mathrm{J}(\mathrm{r}, \mathrm{z}) \mathbf{u}_{\theta} \\
\mathbf{A}_{\mathbf{s c}} & =\mathrm{A}_{\mathrm{sc}}(\mathrm{r}, \mathrm{z}) \mathbf{u}_{\theta}
\end{aligned}
$$

In the 2D axisymmetric case, Biot-Savart's law is still verified but needs to be slightly modified in order to account for the whole geometry as the vector potential $\mathrm{A}_{\mathrm{sc}}$ at a given point of the cross-section depends on the 3D current density distribution. Thus, equation (3) is integrated along the $\theta$-direction to obtain the following analytical formula.

$$
\mathbf{A}_{\mathbf{s c}}(\mathbf{J})=\mu_{0} \int_{\Omega_{\mathrm{c}}} \mathrm{G}_{2 \mathrm{D} \text { axi }} \cdot \mathbf{J} \mathrm{d} \Omega_{\mathrm{c}}
$$

where $\mathrm{G}_{2 \mathrm{Daxi}}$ is called the $2 \mathrm{D}$ axisymmetric Green kernel and is expressed as

$$
\mathrm{G}_{2 \mathrm{D} \text { axi }}=\frac{\mathrm{K}}{4 \pi \mathrm{R}}\left(\left(2-\mathrm{k}^{2}\right) \cdot \mathrm{J}_{1}(\mathrm{k})-2 \mathrm{~J}_{2}(\mathrm{k})\right)
$$

where

$$
\mathrm{K}^{2}=(\mathrm{r}+\mathrm{R})^{2}+\mathrm{h}^{2} \text { and } \mathrm{k}^{2}=\frac{4 \mathrm{rR}}{\mathrm{K}^{2}}
$$

$\mathrm{J}_{1}$ and $\mathrm{J}_{2}$ are the complete elliptic integral of first and second kind respectively and geometrical parameters $\mathrm{r}, \mathrm{R}$ and $\mathrm{K}$ are described in Fig. 1.

The E-J relationship for superconducting materials is described by

$$
\mathbf{E}=\rho(\mathrm{T}, \mathbf{B}, \mathbf{J}) \mathbf{J}
$$

where $\rho$ is the resistivity of the superconducting layer, T represents the temperature and $\mathbf{B}$ is the magnetic flux density. Finally, combining equations (1), (2), (6) and (9) leads to the continuous

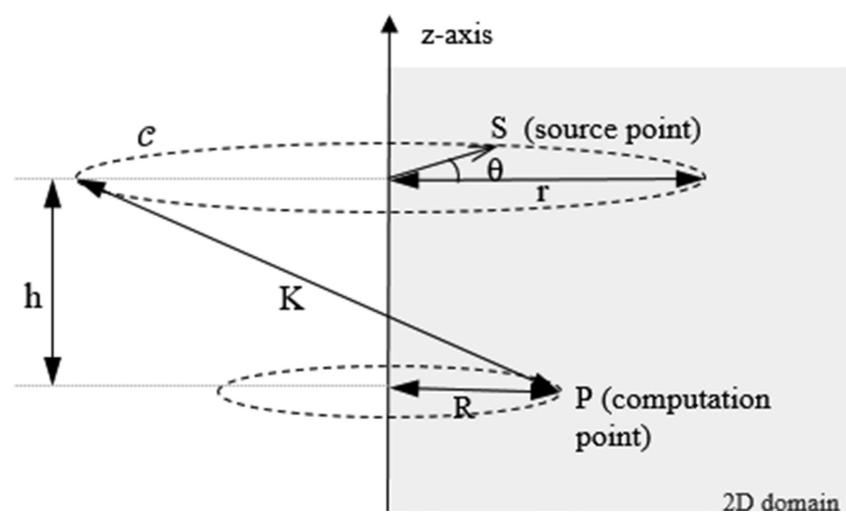

Fig. 1. Green kernel integration strategy.

2D axisymmetric $\mathrm{J}$-formulation.

$$
\begin{aligned}
\rho(\mathrm{T}, \mathbf{B}, \mathbf{J}) \mathrm{J}(\mathrm{r}, \mathrm{z}) & +\mu_{0} \frac{\partial}{\partial \mathrm{t}} \int_{\Omega_{\mathrm{c}}} \mathrm{G}_{2 \mathrm{D} \text { axi }} \cdot \mathrm{J}(\mathrm{r}, \mathrm{z}) \mathrm{d} \Omega_{\mathrm{c}} \\
& =-\frac{\partial \mathrm{A}_{0}(\mathrm{r}, \mathrm{z})}{\partial \mathrm{t}}-\nabla \mathrm{V}
\end{aligned}
$$

\section{B. Circuit Coupling}

Equation (10) is solved using the Volume Integral Method, which requires to mesh all the conducting regions. The unknown $\mathbf{J}$ is interpolated using first order facet shape functions $\mathrm{w}_{\mathrm{f}}$, particularly adapted to divergence-free vector fields [12], which is the case here as the magneto-quasistatic approximation is assumed.

$$
\mathrm{J}=\sum_{\mathrm{k}} \mathrm{w}_{\mathrm{fk}} \mathrm{I}_{\mathrm{k}}
$$

$\mathrm{I}_{\mathrm{k}}$ represents the current flowing through the $\mathrm{k}^{\text {th }}$ facet element. The problem's weak formulation is finally obtained by applying the Galerkin method (weighting functions are equal to interpolation functions).

$$
\left([\mathrm{R}]+\frac{\partial}{\partial \mathrm{t}}[\mathrm{L}]\right)\left[\mathrm{I}_{\mathrm{B}}\right]=\frac{\partial}{\partial \mathrm{t}}\left[\mathrm{A}_{0}\right]+[\Delta \mathrm{V}]
$$

where vectors and matrices are defined as follow (S represents the surface of element $i$ )

$$
\begin{aligned}
\mathrm{R}_{\mathrm{ij}} & =\int_{\mathrm{S}} \mathrm{w}_{\mathrm{fi}} \cdot \rho(\mathrm{T}, \mathrm{B}, \mathrm{J}) \cdot \mathrm{w}_{\mathrm{fj}} \cdot 2 \pi \mathrm{r}_{\mathrm{i}} \mathrm{dS} \\
\mathrm{L}_{2 \mathrm{D} \text { ij }} & =\mu_{0} \int_{\mathrm{S}} \mathrm{w}_{\mathrm{fi}} \int_{\mathrm{S}} \mathrm{G}_{2 \mathrm{D} \text { axi }} \cdot \mathrm{w}_{\mathrm{fj}} \mathrm{dS} / 2 \pi \mathrm{r}_{\mathrm{i}} \mathrm{dS} \\
\mathrm{A}_{0 \mathrm{i}} & =-\int_{\mathrm{S}} \mathrm{w}_{\mathrm{fi}} \cdot \mathrm{A}_{0} \cdot 2 \pi \mathrm{r}_{\mathrm{i}} \mathrm{dS} \\
\Delta \mathrm{V}_{\mathrm{i}} & =-\int_{\mathrm{S}} \mathrm{w}_{\mathrm{fi}} \cdot \nabla \mathrm{V} \cdot 2 \pi \mathrm{r}_{\mathrm{i}} \mathrm{dS}
\end{aligned}
$$

Equation (12) can be interpreted as an equivalent electrical circuit generated based on the dual mesh of the initial mesh of the 2D domain [13]. Barycenter of each element of the primal mesh is considered as a node, circuit branches connect nodes from adjacent elements sharing the same facet. In Equation (12), $\left[\mathrm{I}_{\mathrm{B}}\right]$ vector represents all the branch currents, $[\Delta \mathrm{V}]$ vector is related to branch voltages and represents the average voltage drop 
between two adjacent elements and $\left[\mathrm{A}_{0}\right]$ vector is related to external magnetic field source (if any). $[\mathrm{R}]$ is called the resistivity matrix and $[\mathrm{L}]$ is referred to as the inductive matrix which stores self and mutual inductances between elements computed according to the integral assembly method which consists in the 2D Green kernel integration. Thus, [L] is a full matrix contrary to $[\mathrm{R}]$ which is a sparse one, more convenient for storage and computation performances.

The independent loop search algorithm described in [14] is used to define an incident matrix [M] such as

$$
[\mathrm{M}][\Delta \mathrm{V}]=[0] \Leftrightarrow[\mathrm{M}]^{\mathrm{t}}\left[\mathrm{I}_{\mathrm{L}}\right]=\left[\mathrm{I}_{\mathrm{B}}\right]
$$

The independent loops-based current vector $\left[\mathrm{I}_{\mathrm{L}}\right]$ is introduced as a combination of the branch currents based on the circuit independent loops.

\section{Current Generator Supply}

HTS coils are often supplied by current generators as it allows to easily set the magnetic field to the expected value. From a numerical modeling approach, it is interpreted as an additional constraint defined by

$$
\int_{\mathrm{S}} \mathbf{J} \mathrm{dS}=\sum_{\mathrm{p}} \int_{\mathrm{S}} \mathbf{w}_{\mathrm{fp}} \mathrm{I}_{\mathrm{p}} \mathrm{dS}=\mathrm{I}_{\mathrm{S}}
$$

where $I_{S}$ is the transport current supplied by the current generator and $\mathrm{S}$ is the cross-section area of the superconducting tape. In order to include it in the formulation, the incident matrix [M] is split into two sub-matrices: $\left[\mathrm{M}_{\mathrm{RL}}\right]$ related to the circuit generated based on the physical domain's mesh and $\left[\mathrm{M}_{\mathrm{S}}\right]$ accounting for the current generator considered as an external branch.

$$
[\mathrm{M}]=\left[\mathrm{M}_{\mathrm{RL}} \mathrm{M}_{\mathrm{S}}\right]
$$

Moreover, the voltage drop vector is also divided into an internal voltage drop vector $\Delta \mathrm{V}_{\mathrm{RL}}$ and the voltage drop of the current source $\Delta \mathrm{V}_{\mathrm{s}}$.

$$
[\Delta \mathrm{V}]=\left[\Delta \mathrm{V}_{\mathrm{RL}} ; \Delta \mathrm{V}_{\mathrm{S}}\right]
$$

Therefore, including the current constraint to equation (12) leads to the new set of equations presented in (21).

$$
\begin{aligned}
& \left(\begin{array}{r}
{\left[\mathrm{M}_{\mathrm{RL}}\right]\left([\mathrm{R}]+\frac{\partial}{\partial \mathrm{t}}[\mathrm{L}]\right)\left[\mathrm{M}_{\mathrm{RL}}\right]^{\mathrm{t}}\left[\mathrm{M}_{\mathrm{S}}\right]} \\
{\left[\mathrm{M}_{\mathrm{S}}\right]^{\mathrm{t}}} \\
{[0]}
\end{array}\right) \cdot\left(\begin{array}{c}
{\left[\mathrm{I}_{\mathrm{L}}\right]} \\
{\left[\Delta \mathrm{V}_{\mathrm{S}}\right]}
\end{array}\right) \\
& =\left(\begin{array}{c}
{\left[\mathrm{M}_{\mathrm{RL}}\right] \frac{\partial}{\partial \mathrm{t}}\left[\mathrm{A}_{0}\right]} \\
{\left[\mathrm{I}_{\mathrm{S}}\right]}
\end{array}\right)
\end{aligned}
$$

The unknowns are the independent loops-based currents $\mathrm{I}_{\mathrm{Li}}$ and the voltage value of the current generator $\Delta \mathrm{V}_{\mathrm{S}}$.

\section{Nonlinear E-J Characteristic}

The highly nonlinear $\mathbf{E}-\mathbf{J}$ characteristic is introduced in the J-formulation by using the Power Law model [15].

$$
\rho_{\mathrm{sc}}=\frac{\mathrm{E}_{\mathrm{c}}}{\mathrm{J}_{\mathrm{c}}(\mathrm{T}, \mathbf{B})}\left(\frac{|\mathbf{J}|}{\mathrm{J}_{\mathrm{c}}(\mathrm{T}, \mathbf{B})}\right)^{\mathrm{n}(\mathrm{T}, \mathbf{B})-1}
$$

The current density dependence over the magnetic field at a given temperature operating condition $\mathrm{T}_{\mathrm{op}}, \mathrm{J}_{\mathrm{c}}\left(\mathrm{T}_{\mathrm{op}}, \mathbf{B}\right)=$ $\mathrm{J}_{\mathrm{c}}\left(\mathrm{T}_{\mathrm{op}}, \mathrm{B}, \theta\right)$, is of prime importance in the case of HTS coils

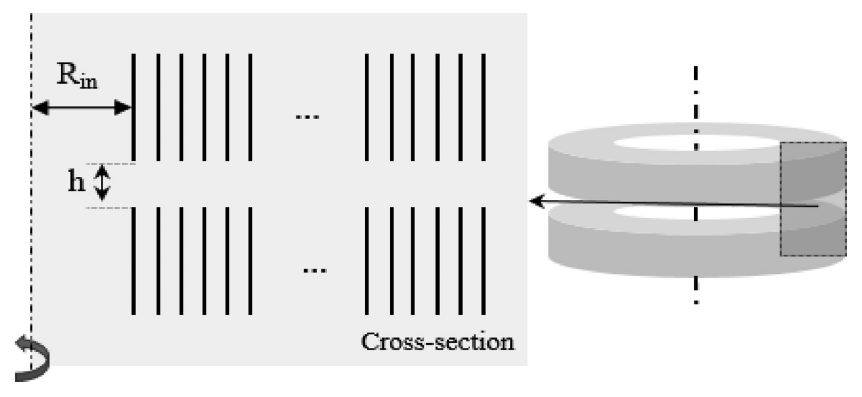

Fig. 2. Double pancake representation for the 2D axisymmetric model.

as each element of the mesh experiences a different local magnetic field. The stiffness coefficient $\mathrm{n}(\mathrm{T}, \mathbf{B})$ is assumed constant. A Newton's method, which represents a powerful iterative root finding algorithm particularly adapted to stiff problems, is chosen to deal with the nonlinear behavior of REBCO tapes.

\section{COMPARISON TO EXPERIMENTAL DATA}

The model presented in Section II has been implemented in an internal multi-method platform called Mipse [16] and dedicated to electromagnetic computations, developed in Java language.

\section{A. Coil Description}

A double pancake coil made of SuperOx $12 \mathrm{~mm}$ REBCO tape was ramped up at a rate of $1 \mathrm{~A} / \mathrm{s}$ in self-field, liquid helium cooling operating conditions. The top pancake has 150 turns and the bottom pancake has 168 turns. The average critical current of the tape has been evaluated based on SuperOx data from Tapestar characterization and was found to be $370 \mathrm{~A}$. The model geometry is reduced to a cross-section of the coil, and only superconducting layers are represented by thin regions (high aspect ratio: 6000), see Fig. 2. Lengths $R_{\text {in }}$ and h equal $96 \mathrm{~mm}$ and $4 \mathrm{~mm}$ respectively. The $\mathrm{n}$-value of the Power Law is set to $25 . \mathrm{J}_{\mathrm{c}}$ variation with the magnetic field is defined using a lift factor approach (defined as the ratio between the critical current $\mathrm{I}_{\mathrm{c}}\left(\mathrm{T}_{\mathrm{op}}, \mathrm{B}, \theta\right)$ measured at a given operation temperature in a given magnetic field and its value at $77 \mathrm{~K}$ self field) derived from SuperOx data [17]: $\mathrm{I}_{\mathrm{c}}\left(\mathrm{T}_{\mathrm{op}}, \mathrm{B}, \theta\right)_{\text {sample }}$ is the critical current map measured in [17] for several operating conditions on a $4 \mathrm{~mm}$ sample and $\mathrm{I}_{\mathrm{c}}(77 \mathrm{~K}, \mathrm{sf})_{\text {sample }}=135 \mathrm{~A}$ is its critical current at $77 \mathrm{~K}$, self-field. The temperature dependency is derived from analytical formulas presented in [18].

\section{B. Results}

The simulated coil voltage shows a trend similar to the experimental data, with identical starting point and quasi-linear rise. However, the slope of the voltage rise is underestimated by $36.3 \%$ compared to the voltage measurements. This might be explained by an overestimation of the lift factor of the tape. Indeed, we assumed that the lift factor remains constant for a given manufacturer production, which might not be correct as recent measurements on SuperOx samples exhibited significant spread of the lift factor value [19]. Another error factor could be a bad estimation of the actual operating temperature (local heat generation due to current leads). Considering all the 


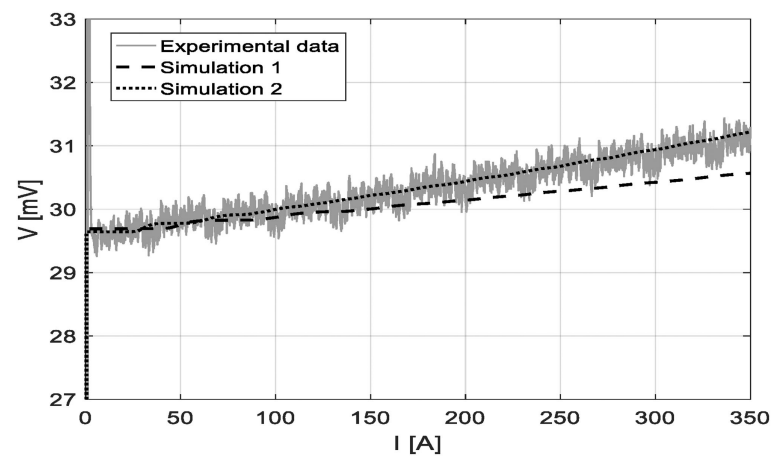

Fig. 3. V-I curve of the double pancake coil obtained by simulations and experimental measurements.
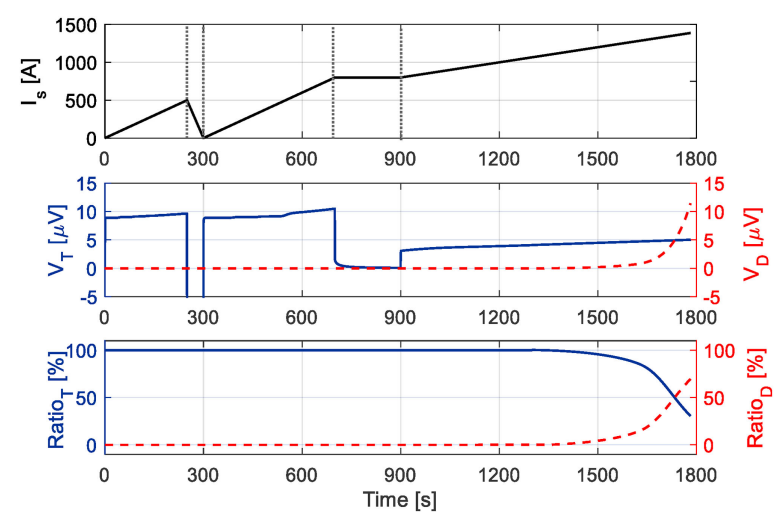

Fig. 4. Current profile of the current generator (top plot), coil's voltage split into a transient voltage $\mathrm{V}_{\mathrm{T}}$ (solid line) and a dissipative voltage $\mathrm{V}_{\mathrm{D}}$ (dashed line) (middle plot) and ratios of each voltage component over the total coil's voltage (bottom plot) - All plots are time-based.

possible errors, simulations have been launched with reduced lift factors. A good agreement is obtained with a lift factor reduced by $28 \%$, as shows Fig. 3 the V-I curve labeled "Simulation 2" (black, dotted line).

\section{Model APPliCATion to CoILs PROTECTION}

The objective of the model is to help to design efficient protection systems by estimating the coil's transient behavior which can hide the dissipative signal used for practical quench detection. This approach is developed on a small-scale coil example made of 25 turns $12 \mathrm{~mm}$ width REBCO tape with a deliberately small inner radius of $5 \mathrm{~mm}$ to maximize the magnetic field concentration in its center as a bigger magnet would do.

\section{A. Transient and Dissipative Voltages Computation}

A typical current profile that could be applied during experiment is defined (see Fig. 4, top plot). No background field is considered and the operating temperature is set to $4.2 \mathrm{~K}$.

The coil's voltage is directly obtained as $\mathrm{V}_{\text {coil }}=-\Delta \mathrm{V}_{\mathrm{S}}$ and its split into an inductive and a dissipative components is derived from the Joule losses computation. Quench models can estimate a safe threshold value to trigger the protection as in [20], but computations are based on dissipative voltage only (see Fig. 4, middle plot, red curve, dashed line), which is most of the time hidden by the inductive signal (depending highly on the coil's geometry and the current profile), as shown in
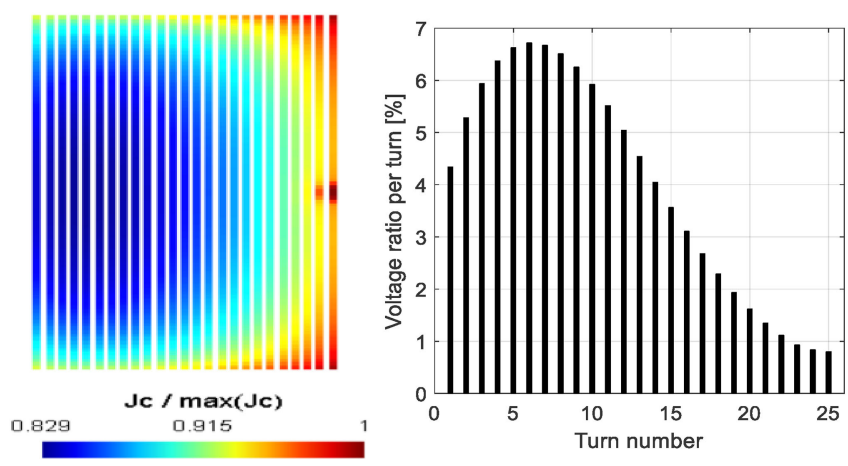

Fig. 5. Critical current density distribution normalized by the maximum value - conductor thickness has been enlarged for visibility (left) and the corresponding voltage ratio per turn Vturn / Vcoil (right) at $t=1757 \mathrm{~s}$.

Fig. 4 (bottom plot). However, if the coil's terminal voltage drop can be estimated beforehand and split into a transient and a dissipative component, then the implementation of a more realistic and accurate threshold value to be compared to the coil's voltage end-to-end measurement can help detection and protection systems design.

\section{B. Local Critical Current Density Variations}

The $\mathbf{J}_{\mathrm{c}}$ dependency over the magnetic field $\mathbf{B}$ tends to weaken some coil's turns that experience locally a higher and/or transverse magnetic field [21]. Thus, the voltage per turn has been computed at $\mathrm{t}=1737 \mathrm{~s}$ (when the dissipative signal becomes significant), so as to investigate the repartition of the total voltage across the turns. Fig. 5 shows the local $\mathrm{J}_{\mathrm{c}}$ distribution (normalized by the $\mathrm{J}_{\mathrm{c}}$ maximum value) over the $2 \mathrm{D}$ domain and the corresponding voltage per turn. It can be seen that innermost turns which experience a higher magnetic field are around 20\% weaker than the outermost turns. It results in a higher voltage contribution of innermost turns to total coil voltage, the most important being for the $6^{\text {th }}$ turn.

Thus, this zone (between turn 4 to turn 8) seems the most vulnerable to a quench initiation reducing the quench propagation investigation from the entire coil to a specific weaker zone.

\section{CONCLUSION}

A transient, nonlinear volume integral formulation allowing easy circuit coupling has been developed for $2 \mathrm{D}$ axisymmetric problems. The model has been applied to an insulated REBCO double pancake coil submitted to a DC current ramp. Quantitatively, the results are not in perfect agreement if we rely on tape characterization from literature, but that was to be expected considering the spread observed in such measurements. A perfect agreement is however obtained for lift factor values that are plausible, which give us confidence in the validity of the model. The model contribution to design of efficient safe protection systems has been demonstrated on a small-scale test case coil. Because the development platform is not designed for computation optimization but rather to allow customization, some computational performance improvements are to be investigated in order to solve bigger systems within reasonable computation times in the future. 


\section{REFERENCES}

[1] W. D. Markiewicz et al., "Design of a superconducting $32 \mathrm{~T}$ magnet with REBCO high field coils," IEEE Trans. Appl. Supercond., vol. 22, no. 3, Jun. 2012, Art. no. 4300704.

[2] S. Awaji et al., "First performance test of a $25 \mathrm{~T}$ cryogen-free superconducting magnet," Supercond. Sci. Technol., vol. 30, no. 6, Jun. 2017, Art. no. 065001 .

[3] X. Deng et al., "An experimental and numerical study on the inductance variation of HTS magnets," IEEE Trans. Appl. Supercond., vol. 25, no. 3, Jun. 2015, Art. no. 4603005 .

[4] F. Sirois, M. Dione, F. Roy, F. Grilli, and B. Dutoit, "Evaluation of two commercial finite element packages for calculating AC losses in 2-D high temperature superconducting strips," J. Phys. Conf. Ser, vol. 97, Feb. 2008, Art. no. 012030.

[5] F. Sirois and F. Grilli, "Numerical considerations about using finiteelement methods to compute AC losses in HTS," IEEE Trans. Appl. Supercond., vol. 18, no. 3, pp. 1733-1742, Sep. 2008.

[6] M. D. Ainslie, W. Yuan, Z. Hong, R. Pei, T. J. Flack, and T. A. Coombs, "Modeling and electrical measurement of transport AC loss in HTS-based superconducting coils for electric machines," IEEE Trans. Appl. Supercond., vol. 21, no. 3, pp. 3265-3268, Jun. 2011.

[7] T. Dai, Y. Tang, J. Li, Y. Zhou, S. Cheng, and Y. Pan, "Study on ac losses of HTS coil carrying ac transport current," Phys. C Supercond. Appl., vol. 426-431, pp. 1339-1342, Oct. 2005.

[8] A. Stenvall, V. Lahtinen, and M. Lyly, "An H-formulation-based threedimensional hysteresis loss modelling tool in a simulation including time varying applied field and transport current: The fundamental problem and its solution," Supercond. Sci. Technol., vol. 27, no. 10, Oct. 2014, Art. no. 104004.

[9] A. E. Ruehli, "Equivalent circuit models for three-dimensional multiconductor systems," IEEE Trans. Microw. Theory Techn., vol. MTT-22, no. 3, pp. 216-221, Mar. 1974.

[10] A. Morandi and M. Fabbri, "A unified approach to the power law and the critical state modeling of superconductors in 2D," Supercond. Sci. Technol., vol. 28, no. 2, Feb. 2015, Art. no. 024004.

[11] A. Morandi, "2D electromagnetic modelling of superconductors," Supercond. Sci. Technol., vol. 25, no. 10, Oct. 2012, Art. no. 104003.
[12] A. Bossavit, "Whitney forms: a class of finite elements for threedimensional computations in electromagnetism," IEEE Proc. Phys. Sci. Meas. Instrum. Manag. Educ. Rev., vol. 135, no. 8, pp. 493-500, Nov. 1988.

[13] T.-T. Nguyen, G. Meunier, J.-M. Guichon, O. Chadebec, and T.-S. Nguyen, "An integral formulation for the computation of 3-D eddy current using facet elements," IEEE Trans. Magn., vol. 50, no. 2, Feb. 2014, Art. no. 7013504

[14] T.-S. Nguyen, J.-M. Guichon, O. Chadebec, G. Meunier, and B. Vincent,"An independant loop search algorithm for solving inductive PEEC large problems," Prog. Electromagn. Res. M, vol. 23, pp. 53-63, 2012.

[15] J. Rhyner, "Magnetic properties and AC-losses of superconductors with power law current-Voltage characteristics," Physica C Supercond., vol. 212, no. 3-4, pp. 292-300, Jul. 1993.

[16] G2ELab, "MIPSE: Modeling of Interconnected Power SystEms," G2ELab, 2018. Accessed: Jan. 30, 2019. [Online]. Available: http://www. g2elab.grenoble-inp.fr/fr/recherche/integral-methods

[17] T. Benkel et al., "REBCO performance at high field with low incident angle and preliminary tests for a 10-T insert," IEEE Trans. Appl. Supercond., vol. 26, no. 3, Apr. 2016, Art. no. 4302705.

[18] C. Senatore, C. Barth, M. Bonura, M. Kulich, and G. Mondonico, "Field and temperature scaling of the critical current density in commercial REBCO coated conductors," Supercond. Sci. Technol., vol. 29, no. 1, Jan. 2016, Art. no. 014002.

[19] S. Samoilenkov et al., "Customised 2G HTS wire for applications," Supercond. Sci. Technol., vol. 29, no. 2, Feb. 2016, Art. no. 024001.

[20] A. Badel, B. Rozier, K. Takahashi, and S. Awaji, "Simulation of local dissipation phenomena in the REBCO insert of the $25 \mathrm{~T}$ CSM magnet: Understanding and preventing destructive thermal runaway," IEEE Trans. Appl. Supercond., vol. 29, no. 5, Aug. 2019, Art. no. 4600605, doi: 10.1109/TASC.2019.2894831

[21] V. Zermeño, F. Sirois, M. Takayasu, M. Vojenciak, A. Kario, and F. Grilli, "A self-consistent model for estimating the critical current of superconducting devices," Supercond. Sci. Technol., vol. 28, no. 8, Dec. 2014, Art. no. 085004 . 